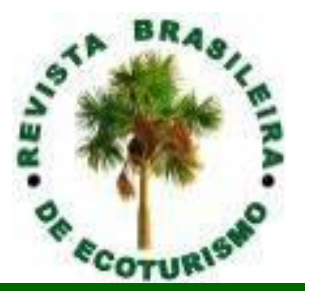

\title{
Ecoturismo de Base Comunitária na Comunidade Quilombola Furnas da Boa Sorte, Corguinho (MS): planejamento e sustentabilidade
}

\section{Community Based Ecotourism in the Quilombola Community Furnas da Boa Sorte, Corguinho (MS, Brazil): planning and sustainability}

\author{
Maristela Benites, Simone Mamede
}

\begin{abstract}
RESUMO: O ecoturismo de base comunitária representa oportunidade central de valorização do ambiente natural, aliada ao protagonismo social, à autonomia e à valorização do território, apoiando-se na perspectiva do turismo como fonte de geração de emprego, renda e dinamização econômica. O trabalho tem como objetivo apresentar as etapas do planejamento participativo para a implantação do ecoturismo de base comunitária na Comunidade Furnas da Boa Sorte, Corguinho/MS, na perspectiva de gestão territorial, desenvolvimento socioeconômico e sustentabilidade. A área de estudo localiza-se na região da Serra de Maracaju, borda leste do Pantanal. As atividades foram desenvolvidas com base na perspectiva freireana, a partir do diálogo permanente e de fazer com a comunidade e não para ela. As etapas metodológicas consistiram de: pesquisa qualitativa, com uso de formulário semiestruturado; visita técnica às residências; e aulas para a administração teórica de conteúdos relacionados aos temas: ecoturismo, sustentabilidade, educação ambiental, hospitalidade, planejamento participativo, agrofloresta, e apresentação de experiências exitosas e inspiradoras em turismo de base comunitária pelo Brasil. Participaram das entrevistas 22 pessoas, representantes de 17 famílias e correspondentes a $42,5 \%$ do número de famílias existentes na comunidade. O território se mostra rico em bens naturais e culturais, o qual pode ser gerido para os propósitos do ecoturismo de base comunitária. Durante todo o processo de diagnóstico e planejamento participativo percebeu-se que os meios de subsistência da comunidade podem estar alinhados à conservação ambiental, com possibilidade de gestão efetiva por agentes de proteção do patrimônio natural e cultural que são os próprios moradores da comunidade. Assim, o Ecoturismo de Base Comunitária permite vislumbrar a possibilidade de práticas de conservação e gestão responsável dos bens naturais, no território em estudo, concorrendo para o aumento da qualidade de vida, dinamização econômica e proteção socioambiental.
\end{abstract}

PALAVRAS-CHAVE: Turismo Comunitário; Protagonismo Social; Território; Cerrado; Desenvolvimento Sustentável. 


\section{ABSTRACT}

Community Based Ecotourism represents a central opportunity for valuing the natural environment, together with social protagonism, autonomy and the valorization of the territory, based on the perspective of tourism as a source of employment generation, financial income and economic dynamism. The objective of this work is to present the participatory planning stages for the implementation of community based ecotourism in the Furnas da Boa Sorte Community, Corguinho, Mato Grosso do Sul, in the perspective of territorial management, socioeconomic development and sustainability. The study area is located in the Serra de Maracaju region, the eastern border of the Pantanal wetland. The activities were developed based on the Freirean perspective, from the permanent dialogue and to do with the community and not for it. The methodological steps consisted of: qualitative research, using semi-structured form; technical visit to the residences; and classes for the theoretical administration of contents related to themes: ecotourism, sustainability, environmental education, hospitality, participatory planning, agroforestry, and presentation of successful and inspiring experiences in community based tourism in Brazil. The interviews were attended by 22 people, representing 17 families and corresponding to $42.5 \%$ of the number of families in the community. The territory is rich in natural and cultural assets, which can be managed for the purposes of community-based ecotourism. Throughout the process of diagnosis and participatory planning it was realized that community livelihoods could be aligned with environmental conservation, with the possibility of effective management by agents of protection of the natural and cultural patrimony that are the residents of the community. Thus, community-based ecotourism allows us to envisage the possibility of conservation practices and responsible management of natural resources in the territory, contributing to an increase in the quality of life, economic dynamization and socio-environmental protection.

KEYWORDS: Community Based Tourism; Social Protagonism; Territory; Cerrado; Sustainable Development.

\section{Introdução}

O ecoturismo é o segmento do turismo que tem sido amplamente difundido nas últimas décadas, principalmente, nos países tropicais, em desenvolvimento ou periféricos, dada a riqueza de belezas naturais, culturais e paisagísticas que dispõem. A prática dessa atividade é particularmente favorecida em áreas naturais que apresentam significativo grau de conservação, pois guardam amostras representativas da biodiversidade local, culturas e tradições que expressam a diversidade sociocultural e biológica de um território e inspiram deleitáveis experiências vivenciais (MENDONÇA; NEIMAN, 2002; MAMEDE et al., 2008; MAMEDE; BENITES, 2008; MAMEDE; BENITES, 2017).

A relação humana com a natureza, mesmo de forma inata, nem sempre é ou foi harmoniosa, isto porque, após o nascimento, o contexto histórico-cultural atuará preponderantemente no desenvolvimento individual e social. Portanto, é necessário mediação para que o vínculo humano com a natureza se mantenha de maneira benéfica a ambos (KEUROGHLIAN; SANTOS, 2014; MAMEDE; BENITES, 2017). 
O ecoturismo preocupa-se em minimizar os impactos negativos tanto no ambiente natural quanto nas comunidades anfitriãs, com o intuito permanente de contribuir na gestão dos bens naturais de forma responsável e coerente, promover educação ambiental e inclusão social, apoiando-se nos princípios do turismo sustentável, isto é, deve ser socialmente justo, economicamente viável e ambientalmente correto, mantendo-se, portanto, intimamente ligado aos aspectos: social, econômico e ambiental, elementos que devem atuar de forma integrada e coordenadamente. O ecoturismo se contrapõe ao turismo massificado em favor da proteção dos bens naturais e da dignidade humana longe, portanto, da espetacularização étnica e da natureza.

O turismo de base comunitária, por sua vez, surge como uma oportunidade de protagonismo social. Esse segmento oportuniza aos grupos sociais, geralmente excluídos de políticas públicas, não só a geração de trabalho e renda, mas também educação, conservação ambiental, saúde e habitação, através da produção de serviços turísticos de forma associativa, comunitária, compartilhada e responsável, constituindo-se de uma nova vertente do turismo que atrai uma demanda específica de turista, não massificada e que se interessa por relações mais harmônicas com a natureza e com as culturas tradicionais locais (ZAMIGNAN; SAMPAIO, 2010). Maldonado (2009) refere-se a um tipo de turismo "com selo próprio", a partir de uma combinação de atributos singulares e originais que 0 visitante só poderá conhecer se visitar uma distinta comunidade. E Coriolano (2006), descreve o turismo de base comunitária como aquele que busca oferecer ao visitante a oportunidade de experienciar a vida local da comunidade, como ela se organiza e se manifesta, fortalecendo a relação entre visitantes e residentes, através de um processo de intercâmbio cultural, trocas de experiências, conhecimentos e saberes. Portanto, o turismo comunitário assume posição de contraponto ao turismo dos megaempreendimentos e surge como forma de evitar que empreendedores externos dominem as comunidades (CORIOLANO, 2009).

O ecoturismo de base comunitária (EBC) se dispõe ao desafio de congregar três vertentes de alta relevância para a sustentabilidade de territórios (ecoturismo, educação ambiental e turismo de base comunitária) que, por estarem unidas, são capazes de gerar efeitos conjugados e, portanto, transcendem àqueles gerados por ação isolada.

Do ecoturismo, por exemplo, se extrai a abordagem do turismo de baixo impacto negativo em termos socioambientais, isto é, interage de forma responsável e harmoniosa com os elementos da natureza, respeita as comunidades visitadas e tem foco na educação ambiental em que a experiência vivenciada pode promover transformação e mudança de hábitos frente ao ambiente e à sociedade. Há maior preocupação e predisposição à conservação do espaço natural.

Já o turismo de base comunitária oferece subsídios no sentido de que o protagonismo e o empoderamento de uma comunidade geram autonomia e autoconfiança para a gestão do turismo e do território, cujo modo de vida e organização podem agregar experiências apreciáveis aos visitantes. 
Portanto, o ecoturismo de base comunitária ganha dimensão mais profunda e redunda em benefícios de caráter social, cultural e ambiental, e, por haver comprometimento com o território e compreensão do seu valor, há melhoria na gestão dos bens naturais e nas práticas de conservação em termos ambientais, e, no âmbito social há protagonismo social, geração de renda, dinamização da economia, autovalorização cultural com perspectivas reais de desenvolvimento local. O resultado final é o avanço na construção de territórios efetivamente sustentáveis.

O ecoturismo de base comunitária pode ampliar as habilidades e competências das comunidades em gerir os bens naturais de seus territórios, recuperando os ambientes degradados e mantendo a integridade daqueles mais conservados. Do ponto de vista social, tem-se a inclusão e a geração de renda e em termos ecológicos, os processos naturais tendem a se manter dinamicamente estáveis ou podem ser melhorados quando em condições de degradação. Irving (2008) destaca que uma natureza desfigurada não constitui atrativo.

LEFF (2009), considera que a luta dos povos tradicionais, originários e camponeses pela sua identidade cultural, seus territórios étnicos, suas línguas e práticas culturais está integrada à valorização de seu patrimônio natural e cultural que dão forma ao ambiente habitado e onde se desenvolveram historicamente, a fim de se reapropriarem de seu potencial produtivo e orientá-lo para o melhoramento de suas condições de existência e de sua qualidade de vida, definidas pelos seus valores culturais e suas identidades étnicas.

É interessante notar as conexões existentes, embora nem sempre percebidas, entre ciência, conservação ambiental e cidadania. DeClerck et al. (2012) pontuam que apesar da aparente separação histórica entre conservação da biodiversidade e esforços para redução da pobreza, há crescente consenso de que a manutenção da diversidade biológica é parte fundamental para redução da extrema pobreza. Além disso, a agregação das comunidades rurais em propostas de conservação pode incrementar substancialmente os esforços de pesquisas em conservação, tornando as práticas e resultados mais efetivos (EATON et al., 2014).

Dessa forma, não há dúvidas quanto aos benefícios proporcionados pelo ecoturismo de base comunitária. No entanto, em primeiro lugar é preciso planejamento, pois são reais os riscos de efeitos negativos ao invés de benéficos, especialmente se forem fundamentados de racionalidade econômica. Para Giraldella e Neiman (2010), o planejamento constitui etapa fundamental para se avaliar quais as melhores decisões para determinada área com vistas às melhores alternativas de uso dos recursos disponíveis que, em áreas naturais, são extremamente sensíveis e necessitam de atenção, pois, sem os devidos cuidados correm o risco de desaparecer. E Ruschmann (1997), propõe que o planejamento turístico consiste em ordenar ações humanas sobre determinado território a fim de se evitar efeitos negativos no uso de recursos, sejam físicos, culturais e sociais, que possam destruir ou reduzir sua atratividade. Desse modo, é possível afirmar que o planejamento é um dos principais mecanismos e etapas que 
viabilizam o uso do território e de seus bens naturais na perspectiva de sustentabilidade.

Para efeito de compreensão e, de forma sucinta, pode-se dizer que o ecoturismo de base comunitária é uma derivação do Turismo de Base Comunitária, isto é, dirige-se a uma comunidade que apresenta organização e dinâmica social próprias, e se pauta na valorização da natureza e de seus atributos, portanto, um segmento turístico que se interessa prioritariamente pela conservação de áreas naturais (patrimônio natural) e da cultura da comunidade receptora (patrimônio cultural), sendo esta, ao mesmo tempo, protagonista, autônoma, empreendedora e gestora da atividade turística, não apenas expectadora ou beneficiária de serviços secundários ou subservientes. Além disso, representa forma de inclusão social, onde jovens, adultos, idosos, mulheres e homens podem trocar saberes e se envolver nas atividades, com retorno financeiro digno, satisfação pessoal e menor risco de degradação do socioambiente.

Este trabalho tem como objetivo apresentar as etapas do planejamento participativo para a implantação do ecoturismo de base comunitária na Comunidade Furnas da Boa Sorte, Corguinho/MS, na perspectiva de gestão territorial, desenvolvimento socioeconômico e sustentabilidade.

\section{Material e Métodos}

\section{Área de estudo}

O projeto foi desenvolvido no município de Corguinho/MS, tendo como objeto de estudo a Comunidade Quilombola Furnas da Boa Sorte. O município de Corguinho localiza-se no planalto da Serra de Maracaju, e em função de sua posição geográfica, desempenha papel importante na dinâmica física, biológica e na orografia do Cerrado e do Pantanal. A região integra a Bacia do Alto Paraguai (BAP), cujos mananciais abastecem a planície pantaneira e, por estar em área de transição imediata com a planície pantaneira, os efeitos de fenômenos físicos, de ordem natural e antrópica, no planalto refletem diretamente no Pantanal. Portanto, trata-se de uma região estratégica para a conservação do Pantanal e do Cerrado.

A comunidade Quilombola Furnas da Boa Sorte detém território de aproximadamente 1.400 hectares em bioma de Cerrado, cuja localidade dispõe de exuberante riqueza tanto do ponto de vista paisagístico quanto cultural e biológico. Em decorrência disso, é possível se encantar com os cenários de rara beleza e imediatamente perceber o potencial turístico imanente e que pode ser desenvolvido nesse território tradicional quilombola. Essa região integra a Região Turística Caminho dos Ipês, da qual participam 10 municípios do Mato Grosso do Sul (MAMEDE et al., 2017).

A comunidade Quilombola Furnas da Boa Sorte constitui-se de 40 famílias que vivem principalmente da agropecuária de subsistência e da prestação de serviços nas propriedades rurais adjacentes. Está organizada em quatro núcleos habitacionais denominados: Carrapato, Boa Sorte, 
Caridade e São Sebastião. A área de entorno da comunidade tem sido explorada pelo turismo ufológico há vários anos, mas sem incentivos ao turismo de base comunitária latente na comunidade.

\section{Métodos}

O conjunto de ações do planejamento participativo do ecoturismo de base comunitária na Comunidade Furnas da Boa Sorte foi delineado junto com os moradores em 2016 por meio de um curso de treinamento dividido em módulos. O primeiro módulo intitulado Ecoturismo de Base Comunitária: planejamento e sustentabilidade contou com a participação de membros da comunidade quilombola, acadêmicos, professores, profissionais do turismo e de outras áreas como: direito, biologia, pedagogia, comunicação, geografia, arte, gestão e administração.

As atividades foram desenvolvidas com base na perspectiva freireana que prioriza o diálogo e o fazer com a comunidade e não para ela (FREIRE, 2005), e um modelo de aprendizagem que instiga a inteligência coletiva em um dinâmico e permanente ciclo de "aprender-fazendo-uns-com-os-outrosde-forma-horizontal" que integra vários saberes e une teoria à prática e ambas se transformam dialeticamente, como proposto por Leff (2002). Assim, as etapas metodológicas consistiram de: pesquisa qualitativa, por meio de entrevista junto à comunidade, utilizando-se de formulário semiestruturado; visita técnica às residências; aulas com administração teórica de conteúdos relacionados aos temas: ecoturismo, sustentabilidade, educação ambiental, hospitalidade, planejamento participativo e agrofloresta; e apresentação de experiências exitosas e inspiradoras em turismo de base comunitário no contexto nacional.

Foram realizadas ainda: atividades participativas de diagnóstico e mapeamento das moradias disponíveis para hospedagem domiciliar e acampamento ao ar livre - camping; e diagnóstico e mapeamento de serviços e produtos oferecidos pela comunidade conforme a sazonalidade local. Para o mapeamento foi utilizado e adaptado o green map comunidade, cultura e ambiente, elaborado de forma coletiva e constituindo um produto socioambiental e cultural de identificação e de localização de diferentes atrativos distribuídos no território da comunidade. As atividades metodológicas estão representadas na Figura 1. 


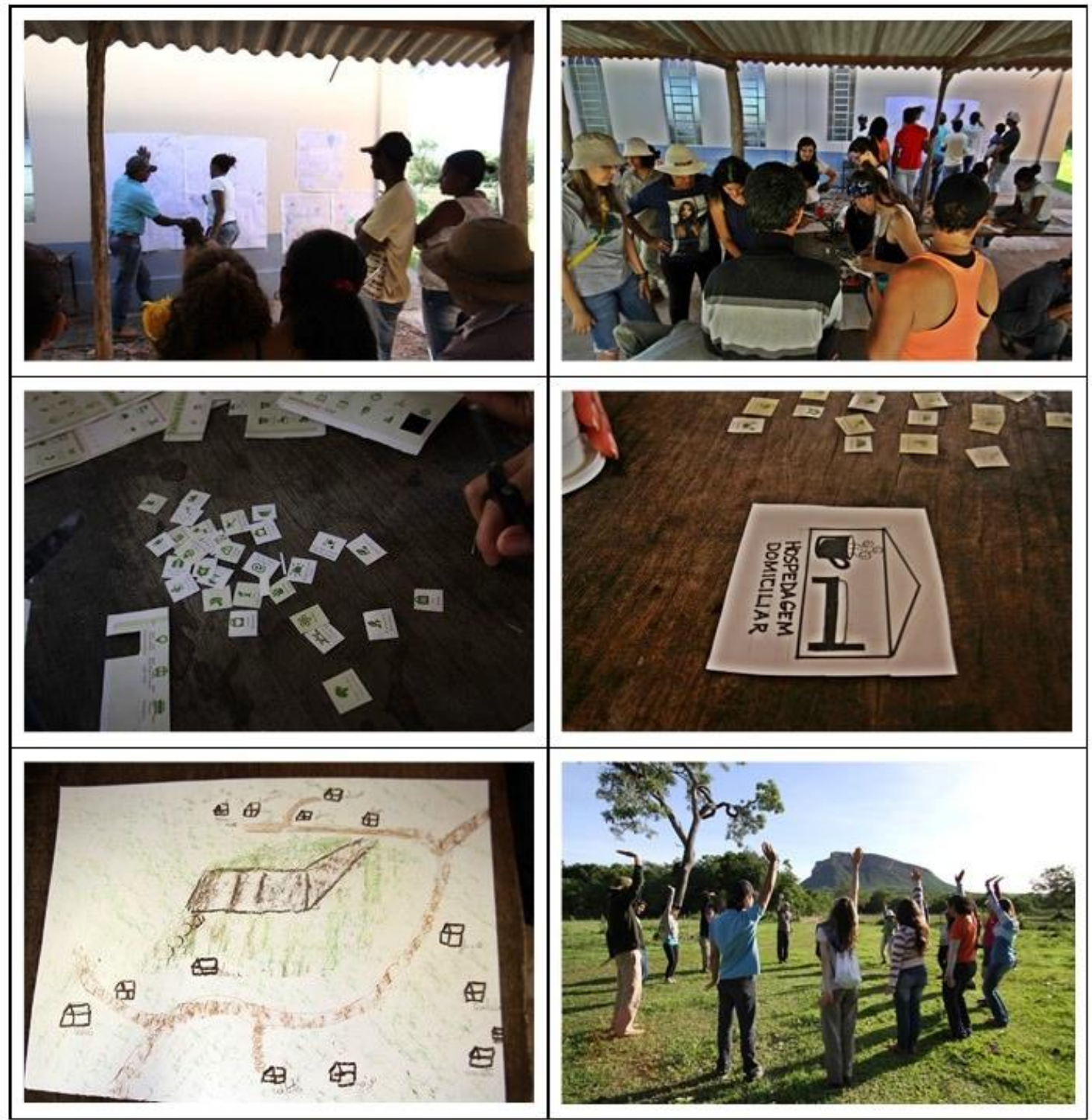

Figura 1: Registros da metodologia aplicada durante a pesquisa.

Figure 1: Records of the methodology applied during the research.

\section{Resultados e discussão}

\section{Inclusão social e sustentabilidade}

Entre os resultados do planejamento para a implantação do ecoturismo de base comunitária na Comunidade Quilombola da Boa Sorte está a formação para o empoderamento e protagonismo da comunidade associado à conservação dos bens naturais. Esse processo formativo tem sido monitorado, a fim de contribuir para melhorias e para que o arranjo turístico que vem sendo concebido avance em identidade e autonomia e que permita a melhoria da qualidade dos serviços de ecoturismo e da melhor qualidade de vida dos moradores locais.

A inclusão social, as ações de fortalecimento de autoestima, o orgulho e a identidade cultural da comunidade são fatores de alta relevância dentro 
do processo de formação do ecoturismo de base comunitária. Irving (2009) afirma que a valorização da cultura local constitui parâmetro indispensável em turismo de base comunitária, enquanto objetivo de afirmação de identidades e pertencimento. Embora somente nos últimos anos o tema inclusão social tenha sido incorporado ao discurso político em nível de gestão pública (IRVING, 2008; IRVING, 2009; SANCHO; IRVING, 2010), o mesmo sempre foi elemento essencial para o empoderamento comunitário e definição de seu próprio destino em busca da sustentabilidade local.

Desde o planejamento, o tema sustentabilidade deve permear as ações propostas e servir de fundamentação, conforme aponta Leff (2009, p.204).

\begin{abstract}
O desenvolvimento sustentável transcende a finalidade de capitalizar a natureza e de ecologizar a ordem econômica, mas se fundamenta na socialização da natureza e no manejo comunitário dos recursos, baseados em princípios de diversidade biológica e cultural, onde democracia e equidade são elementos subjacentes às condições culturais e políticas de reapropriação da natureza.
\end{abstract}

O segmento de ecoturismo de base comunitária na Comunidade Quilombola Furnas da Boa Sorte busca representar uma forma de negação ao turismo do não lugar, visto que o convívio e experiência podem gerar novas representações a esse turismo e cada lembrança pode remeter ao lugar trazendo os sentimentos de responsabilidade, de comprometimento, de vínculo afetivo e de valorização. Isto se inscreve no conceito de topofilia, compreendido como o elo afetivo entre pessoa e lugar, relativo, portanto, às experiências no espaço vivido (TUAN, 2015).

Vale ressaltar, a participação de profissionais de forma interdisciplinar, no processo de formação coletiva, o que tem contribuído para integração social e para a difusão do ecoturismo de base comunitária com alto potencial no Mato Grosso do Sul, demonstrando como o valor à diversidade pode influenciar positivamente no processos de planejamento, de qualificação e de construção coletiva do turismo.

É interessante notar neste estudo, a relação entre o singular e o universal (ALVES, 2003), ou seja, a interação entre a capacidade dos grupos sociais recriar espaços múltiplos de sociabilidade (HAESBAERT, 2004), em reflexo do universal, o que deve estar presente na análise ora postulada sobre o ecoturismo de base comunitária. Sob essa ótica, não se pode desprezar o fato de que o capital busca maneiras para seu domínio, sendo os bens naturais e a força de trabalho elementos fundamentais do processo de produção. Segundo Alves (2003), o singular é a manifestação, no espaço convencionado, de como leis gerais do universal operam dando-lhe uma configuração específica. 


\section{Diagnóstico participativo}

Ao todo foram entrevistados 22 moradores da comunidade quilombola Furnas da Boa Sorte, representantes de 17 famílias equivalente a $42,5 \%$ das famílias da comunidade $(n=40)$. Destas, $36,3 \%(n=8)$ corresponderam ao núcleo Carrapato, 31,9 \% $(n=7)$ ao núcleo Boa Sorte, $18,1 \%(n=4)$ ao núcleo São Sebastião e $13,7 \%(n=3)$ pertenciam ao núcleo Caridade. Dos entrevistados $99,5 \% \quad(n=21)$ demonstraram interesse em participar do processo de ecoturismo de base comunitária, seja a partir da predisposição em participar das ações de qualificação, formação, seja oferecendo hospedagem domiciliar, camping, refeição ou outros produtos e serviços, como rapadura, queijo, artesanato, condução em trilhas dentro do território quilombola, entre outros em que se reconheçam como atores dessa pretensa cadeia produtiva. Apenas um morador não se mostrou interessado diretamente devido à idade avançada, mas, ainda assim, qualificou a ação como importante para o desenvolvimento da comunidade, afirmando que os mais jovens devem continuar empreendendo esforços para esse fim, sendo este o momento oportuno.

Quando questionados sobre o elemento mais representativo da comunidade $63,6 \%(n=14)$ afirmaram que o Morro de São Sebastião, também conhecido por Morro da Boa Sorte, é o elemento mais simbólico da comunidade, pois devido a sua grandiosidade, onde quer que se esteja, dentro do território da comunidade, é possível observá-lo em um de seus ângulos e orientar-se por ele (Figura 2). Portanto, é identificado simbolicamente pela comunidade como grandeza, força e elemento de orientação geográfica.
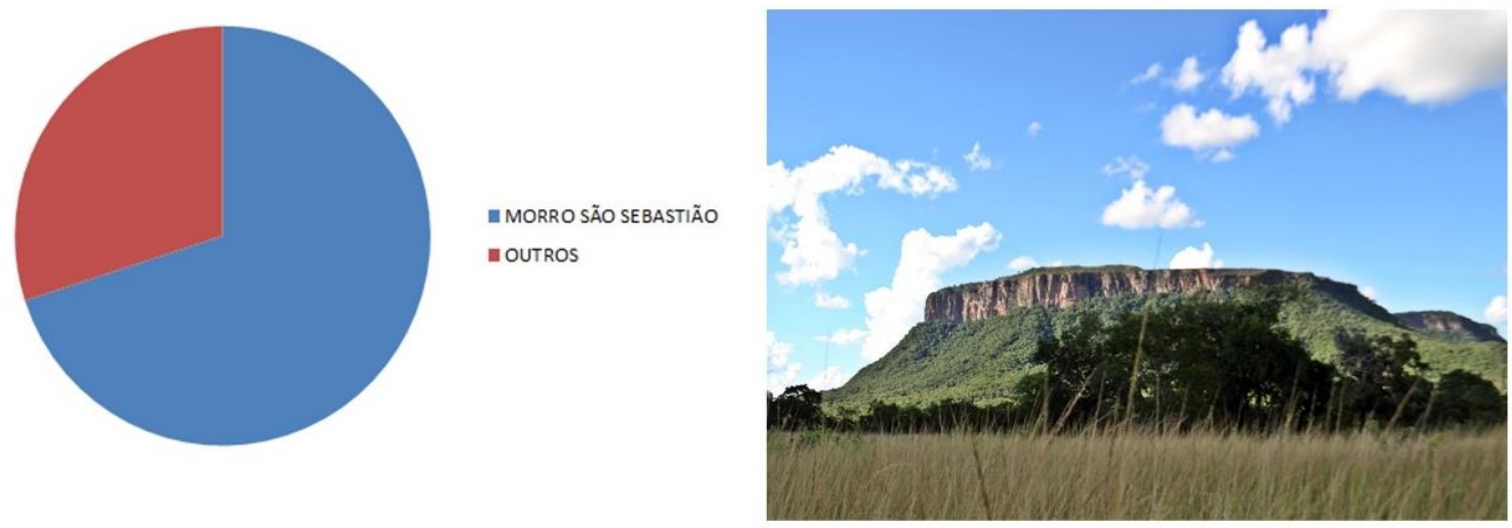

Figura 2: Elemento mais representativo da comunidade quilombola Furnas da Boa Sorte. Morro de São Sebastião, também conhecido como Morro da Boa Sorte.

Figure 2: Most representative element of the quilombola community of Furnas da Boa Sorte. Morro de São Sebastião, also known as Morro da Boa Sorte.

Outros elementos representativos também foram lembrados, dentre os quais: as roças, a rapadura, o frango caipira, o guisado de mandioca e outros signos que, de alguma forma, pertencem ao universo e ao cotidiano da comunidade. É interessante perceber o vínculo com o território. Para 
Haesbaert (2004) território está vinculado ao poder, mas não somente no sentido tradicional de poder político, de dominação, como também no sentido simbólico de apropriação, este motivado pelo espaço-tempo vivido. O mesmo autor considera que a territorialidade está intimamente ligada ao modo como as pessoas utilizam a terra, como elas próprias se organizam no espaço e como elas dão significado ao lugar. Da significação do lugar surge o vínculo afetivo.

No que se refere ao conhecimento sobre a história da comunidade $54,5 \%$ dos entrevistados informaram que desconheciam a história da comunidade, enquanto $41 \%$ afirmaram conhecer e $4,5 \%$ disseram conhecer parcialmente. Foi observado que o grupo de entrevistados de faixa etária mais jovem (entre 16 e 25 anos) não tinha conhecimento da história da comunidade. Ressalta-se, no entanto, a necessidade de valorização das raízes históricas a serem transmitidas para os mais jovens para que não corram o risco de perda de identidade e das referências históricas da comunidade.

Entre os atrativos considerados como mais relevantes pela comunidade estão: as paisagens naturais, o contato com a natureza, a vida selvagem, trilhas e banho de cachoeira (Figura 3). Vale ressaltar, que a cachoeira não se localiza dentro do território quilombola e sim no entorno.

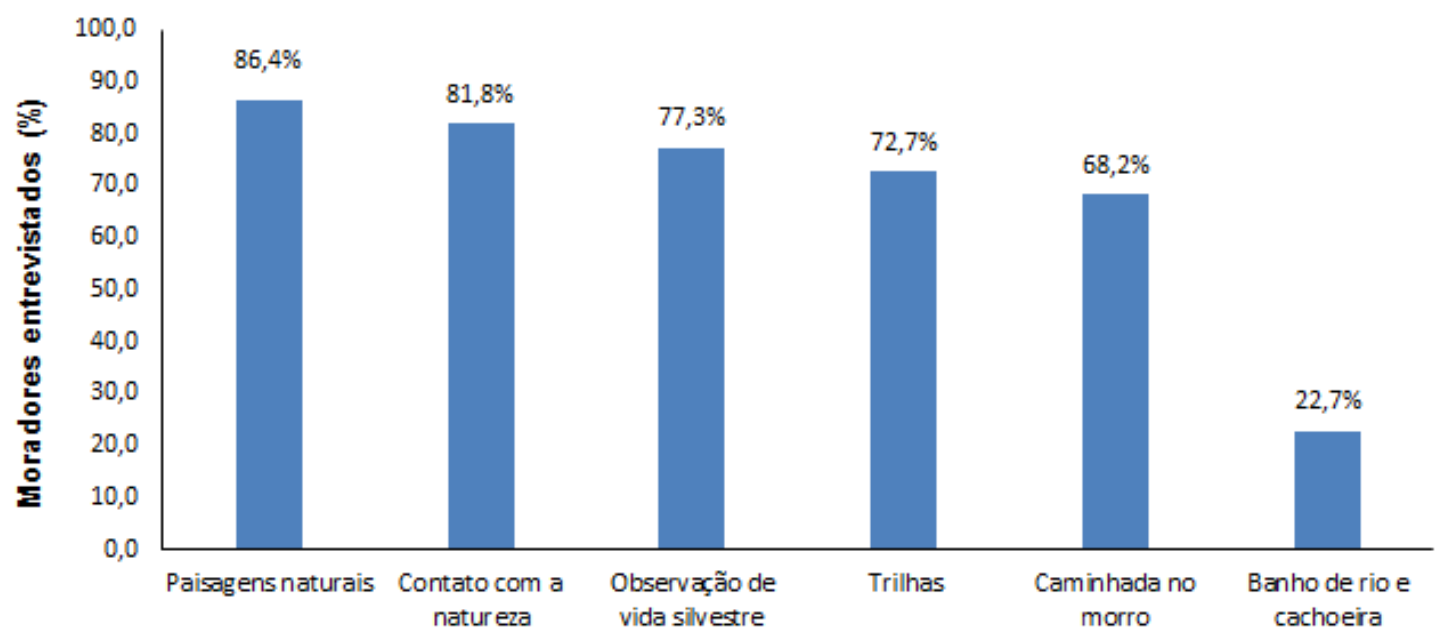

Figura 3: Atrativos considerados pela comunidade como importantes para o EBC.

Figure 3: Attractiveness considered by the community as important for the Community Based Ecotourism.

Esses dados corroboram com as práticas ecoturísticas mais valorizadas pelos visitantes da Região Turística Caminhos dos Ipês onde se localiza a comunidade quilombola Furnas da Boa Sorte (MAMEDE et al., 2017). Nesse estudo, os autores observaram que $47,4 \%$ dos turistas afirmaram que a contemplação da natureza é a atividade ecoturística mais atrativa na região.

Todos os entrevistados da comunidade consideraram importante a existência de sinalização nas residências que demonstraram interesse em 
participar do processo de implantação do ecoturismo de base comunitária. Consideraram relevante principalmente a sinalização das residências habilitadas para camping, hospedagem domiciliar ou algum tipo de produto como refeições e artesanato.

Os entrevistados demonstraram interesse em novas formações e qualificações como: gastronomia e culinária (36,4\%), observação de vida selvagem e fotografia (18,2\%), artesanato e cultura (13,6\%), agroecologia e educação ambiental (13,6\%), além de outros, como doma racional de equinos - visto terem pequena criação desses animais e de bovinos -, gestão do conhecimento e troca de saberes sobre história, botânica e biologia, primeiros socorros, idiomas e formação em guia de turismo ou condutor de visitantes no território.

Quando o tema foi apoio institucional e governamental, todos abordaram que a comunidade não tem nenhum tipo de apoio ou incentivo governamental para desenvolver atividades relacionadas ao turismo. Necessitam de apoio e de políticas públicas locais que deem condições à comunidade para terem autonomia em processos que os ajudem a empreender nesse segmento. Cruz (2005) aborda sobre uma política pública do turismo que historicamente negligencia o território, apesar de o espaço ser o principal objeto de consumo deste setor. Isso demonstra a necessidade de políticas públicas eficazes que permitam, ao mesmo tempo, condições dignas aos moradores locais e a não diluição do lugar.

\section{Planejamento Participativo}

O diagnóstico participativo das potencialidades para ecoturismo de base comunitária a partir da realidade local oportunizou à comunidade e aos demais participantes o conhecimento sobre a biodiversidade e a cultura local, promovendo ainda, a troca de saberes que alicerçaram o planejamento participativo. De acordo com Cruz (2008) é a partir da utilização de técnicas de planejamento participativo que a comunidade é instigada a refletir criticamente sobre o uso do seu território e o modelo de desenvolvimento do turismo. A conexão entre o planejamento e o desenvolvimento do turismo sustentável visa satisfazer as necessidades econômicas, sociais e estéticas sem colocar em risco a continuidade dos recursos turísticos designadamente culturais e ecológicos (MARUJO; CARVALHO, 2010).

O planejamento turístico comunitário é uma forma de desenvolver diretrizes junto à comunidade, atendendo as necessidades sociais e expandido o setor turístico (BURSZTYN, 2004). E, no caso de planejamento participativo do ecoturismo de base comunitária, o modelo delineado pela comunidade pode assegurar a participação, o controle e o empoderamento comunitário no processo de construção e gestão do turismo respeitando elementos culturais, sociais e ambientais, com um forte apelo à educação ambiental.

Durante o planejamento participativo houve preocupação frequente entre moradores e participantes não-moradores "como assegurar a distribuição de renda entre todos os envolvidos no ecoturismo de base 
comunitária, de forma justa e equilibrada"? Para responder a essa pergunta e preocupação foram discutidas alternativas de criação de agência de turismo na comunidade, o fortalecimento da associação comunitária, distribuição justa das demandas relacionadas ao turismo, modelos de divulgação compartilhada, tarifa única, entre outras possibilidades e instrumentos de gestão que possam assegurar distribuição justa de renda entre todos os envolvidos, de modo a evitar o ciclo vicioso de geração de riqueza concentrada aos de maior posse, característica do modelo capitalista.

O mercado capitalista produziu valor destruindo a natureza, e seu caráter cíclico agora o faz produzir valor protegendo a natureza. A questão não é saber das verdadeiras intenções do mercado no que diz respeito à proteção do patrimônio natural e cultural, mas como será repartida a riqueza gerada pela exploração econômica da natureza protegida. A história tem evidenciado que o mercado não conseguiu distribuir a riqueza gerada pela exploração da natureza, quando esta só adquiria valor enquanto produto transformado pelo trabalho humano. Terá ele agora capacidade de distribuir a riqueza gerada pela nova onda de exploração da natureza? (LAYRARGUES, 2018).

Portanto, é preciso senso de justiça para administrar recursos financeiros advindos da natureza e do trabalho, sem que 0 valor mercadológico incorporado aos bens naturais e culturais sobreponha aos demais valores naturais, culturais e simbólicos existentes na comunidade.

Os diálogos e a troca de saberes junto à comunidade foram elementos condutores para o entendimento de conceitos e sua distinção, tais como: turismo, ecoturismo, turismo de massa, turismo de base comunitária, ecoturismo de base comunitária, além de reconhecerem as potencialidades, os desafios, os impactos positivos e negativos dentro de um processo de implementação turística. É importante não ideologizar e não observar ingenuamente esses processos, compreendendo os desafios e buscando estratégias adequadas para enfrentá-los.

São muitos os desafios para a implantação e consolidação do ecoturismo de base comunitária, principalmente quando a cultura turística está ausente na comunidade. Embora haja potencialidades há, pelo menos, dois limites opostos evidentes e que tensionam essa proposição, os quais necessitam de ampla reflexão. De um lado, a oportunidade de transformação e ascensão social, com vistas à autonomia e ao protagonismo socioeconômico, por outro, não se deve ignorar que o turismo é um fenômeno econômico e esta representação é inegável e não deve ser ingenuamente interpretada ou romantizada. E, possivelmente, um terceiro limite se manifesta que é a proteção ambiental, ponto de alta sensibilidade e que requer devida atenção.

A ausência de cultura turística, pode ser revertida, no entanto, como oportunidade para que, desde o início do planejamento, haja construção 
dialógica, participativa e alicerçada nos princípios de cooperação, solidariedade, alteridade e sustentabilidade. Na contramão, a mesma ausência pode dar lugar a resultados opostos se mal compreendidos, desamparados por políticas públicas, mal planejados ou mal orientados, sob pena de se reafirmar o turismo hegemônico, de exploração descomprometida dos bens naturais, sobretudo capitalista, onde a mercantilização, o lucro e a individualidade são as motivações finais, modelo muitas vezes travestido de ecoturismo. No entanto, se existe vocação natural no que se refere ao potencial paisagístico, cultural e de biodiversidade, se a comunidade está organizada, se os interesses são compartilhados, há políticas públicas e há disposição e engajamento para enfrentar os desafios, o pretenso sucesso sob a ótica da sustentabilidade tem grande chance de se concretizar, pela compreensão de seus princípios e valores. Segundo Irving (2009, p. 112):

Embora frequentemente atores externos funcionem como "indutores" do turismo de base comunitária, se a iniciativa não tiver motivação endógena e expressar o desejo dos grupos sociais locais, ela certamente não atenderá às demandas de desenvolvimento local e nem contribuirá para o protagonismo social, condição essencial para este tipo de turismo.

\section{Mapeamento dos produtos turísticos e oferta sazonal}

O mapeamento turístico participativo engloba tanto as questões de infraestrutura básica, quanto temas específicos como preservação do patrimônio natural e cultural, políticas públicas específicas, entre outros (CASTRO; FORTUNATO, 2014). Esse retrato poderá permitir que a própria comunidade, e até mesmo os turistas, percebam o panorama diverso de atrativos oferecidos na comunidade e a forma com que se relacionam espacialmente com a comunidade.

Mapear de forma participativa foi também uma forma de instigar o diálogo entre os atores envolvidos, assim como qualificar os produtos e serviços ecoturísticos na comunidade da Boa Sorte, ao mesmo tempo que se buscou valorizar e aprimorar o olhar para a identificação dos inúmeros serviços ecossistêmicos. Neste processo, dois elementos foram considerados pela comunidade como principais: a paisagem natural (bens naturais) e a cultura local (modo de vida da comunidade).

A maioria dos integrantes da comunidade que participaram do planejamento participativo e do diagnóstico $(86,3 \%)$ informaram ter produtos e/ou serviços para oferecer ou prestar no processo de ecoturismo de base comunitária. Entre os produtos destacaram-se: culinária típica e produção de artesanatos, como trançados, tapetes, cestarias, e produtos alimentícios como rapadura, farinha de mandioca, garapa, hortaliças, frutas sazonais, pães, sopa paraguaia, bolo caseiro, bolo de mandioca, doces caseiros, frango caipira, guisado de mandioca, além de hospedagem domiciliar, camping e o serviço de condução em trilhas (Figura 4). 


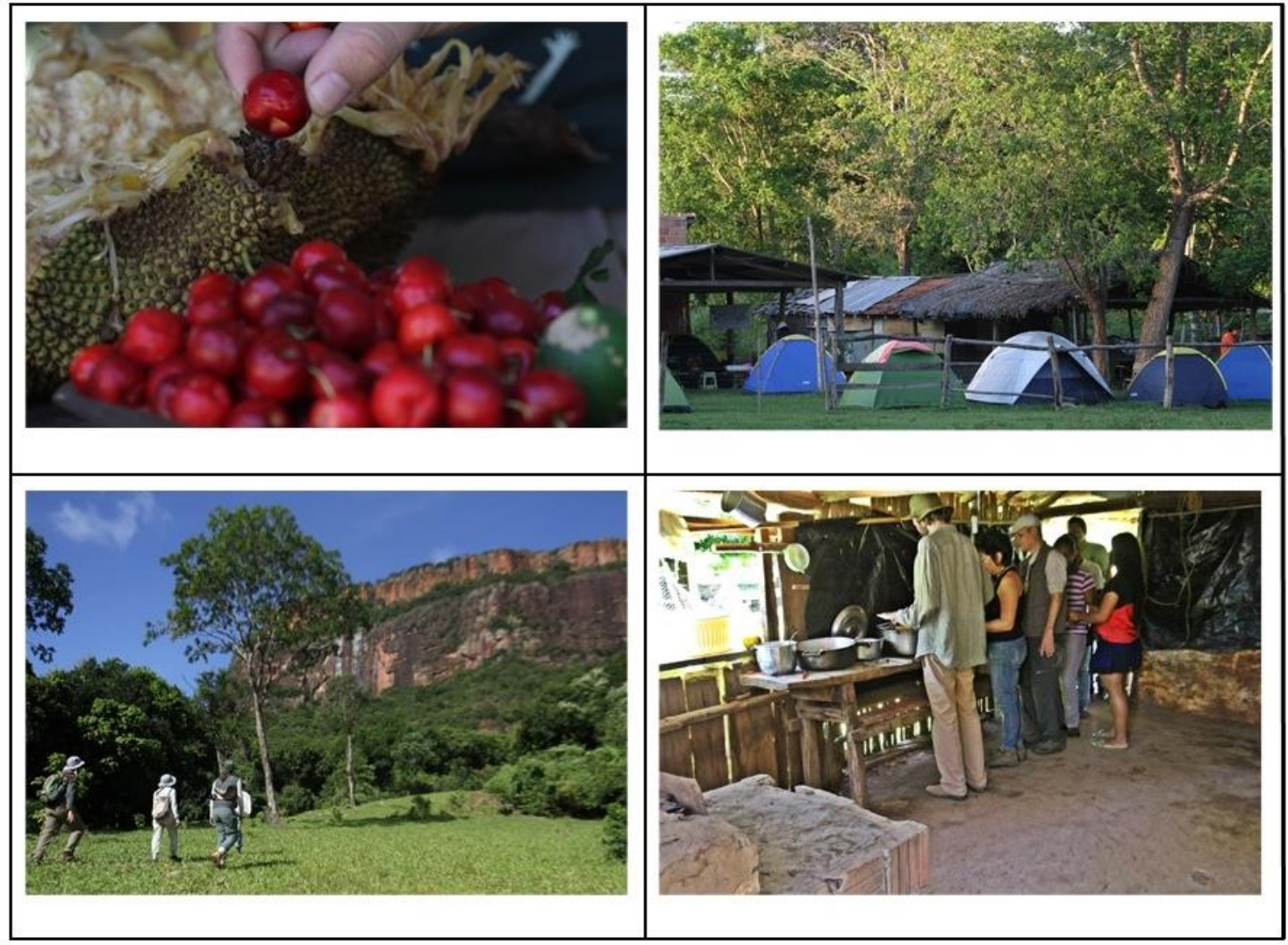

Figura 4: Alguns produtos e serviços oferecidos pela comunidade para o ecoturismo de base comunitária. Fotos: Simone Mamede.

Figure 4: Some products and services offered by the community for community based ecotourism. Photos: Simone Mamede.

O calendário sazonal que retratou a oferta dos serviços hospedagem domiciliar, camping e refeições, mostra que durante os doze meses do ano há disponibilidade desses três produtos na comunidade, sendo 06 (seis) áreas de camping abertas no período de janeiro e julho e três durante todo o período do ano. Os acampamentos têm limite entre 10 a 30 pessoas, números estes estabelecidos pelos próprios moradores. Três residências têm possibilidade de fornecer hospedagem domiciliar no período de janeiro e fevereiro e cinco residências oferecerão hospedagem domiciliar no período de março a dezembro. Aquelas que sinalizaram impossibilidade de hospedagem no mês de janeiro justificaram que o mês representa período de férias e tanto podem receber familiares como também podem se ausentar para viagens. Três famílias se propuseram a oferecer refeições diárias em todo o período do ano desde que a reserva seja feita com antecedência (Figura 5). 


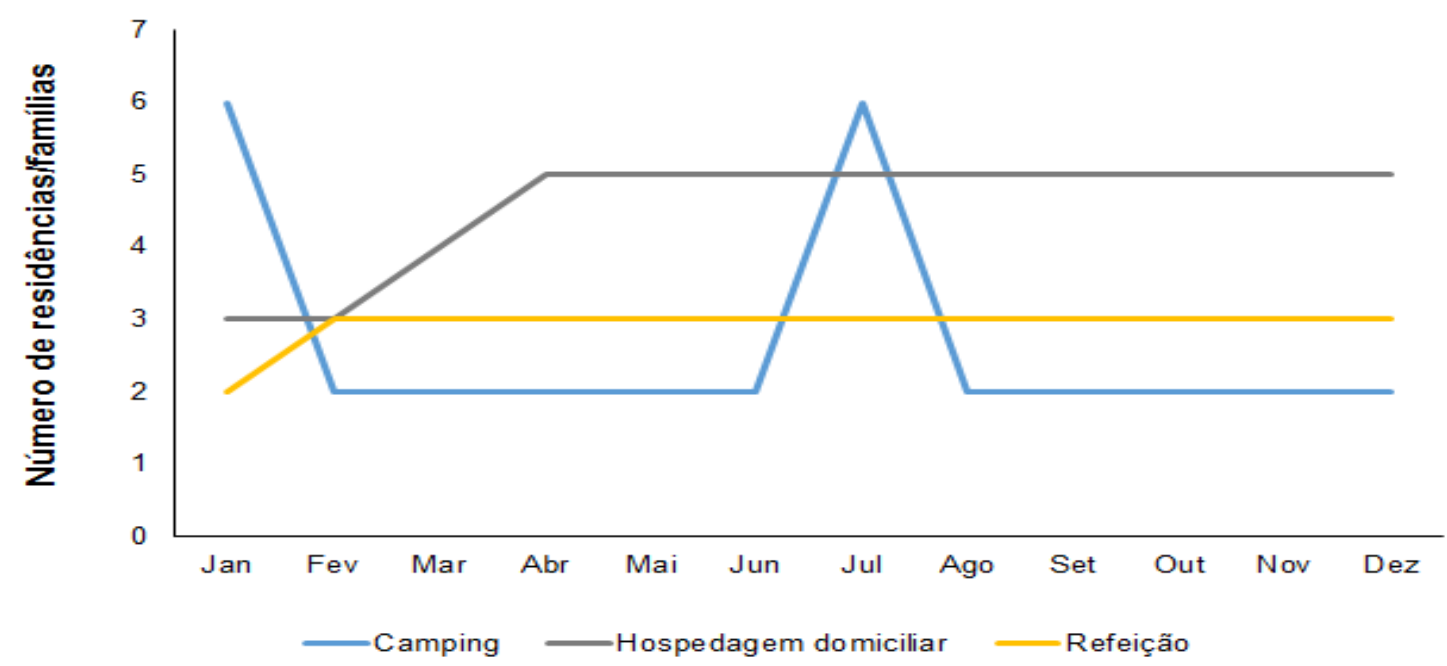

Figura 5: Oferta sazonal de hospedagem domiciliar, área de camping e refeições.

Figure 5: Seasonal offer of homestay, camping area and meals.

O Morro de São Sebastião, também conhecido como Morro da Boa Sorte, é um lugar de beleza cênica singular, no entanto, o passeio pelo local é sugerido a partir de abril, no término do período de chuvas na região. Com relação aos produtos alimentícios provenientes do pomar e da horta, o período de abril a maio sinaliza a colheita dos cítricos laranja e ponkan. Já a manga, fruta bastante apreciada localmente, está restrita ao final do ano, no período de outubro a dezembro (Quadro 1). Outros frutos menos representativos no uso culinário da comunidade não foram incluídos na análise quantitativa, tais como: pequi, jatobá, bocaiúva, guavira, tamarindo e outros, no entanto, podem ser encontrados na região.

Quadro 1: Calendário sazonal para oferta de produtos alimentícios na comunidade quilombola Furnas da Boa Sorte.

Board 1: Seasonal calendar for the supply of food products in the Quilombola community Furnas da Boa Sorte.

\begin{tabular}{|l|l|l|l|l|l|l|l|l|l|l|l|}
\hline Produtos & Jan & Fev & Mar & Abr & Mai & Jun & Ago & Set & Out & Nov & Dez \\
\hline Laranja/ponkan & & & & $\mathrm{x}$ & $\mathrm{x}$ & & & & & & \\
\hline Abacaxi & & & & & & & & & & & $\mathrm{x}$ \\
\hline Manga & $\mathrm{x}$ & & & & & & & & & $\mathrm{x}$ & $\mathrm{x}$ \\
\hline Produtos da horta & & & & $\mathrm{x}$ & $\mathrm{x}$ & $\mathrm{x}$ & $\mathrm{x}$ & $\mathrm{x}$ & $\mathrm{x}$ & $\mathrm{x}$ & $\mathrm{x}$ \\
\hline Banana & & & & & & & & $\mathrm{x}$ & $\mathrm{x}$ & $\mathrm{x}$ & $\mathrm{x}$ \\
\hline Mandioca & & & & & $\mathrm{x}$ & $\mathrm{x}$ & $\mathrm{x}$ & $\mathrm{x}$ & $\mathrm{x}$ & & \\
\hline Milho & $\mathrm{x}$ & $\mathrm{x}$ & $\mathrm{x}$ & & & & & & & $\mathrm{x}$ & $\mathrm{x}$ \\
\hline Feijão & & & & & & & & & $\mathrm{x}$ & $\mathrm{x}$ & $\mathrm{x}$ \\
\hline Jaca & $\mathrm{x}$ & & & & & & & & & $\mathrm{x}$ & $\mathrm{x}$ \\
\hline Acerola & $\mathrm{x}$ & $\mathrm{x}$ & $\mathrm{x}$ & $\mathrm{x}$ & & & & $\mathrm{x}$ & $\mathrm{x}$ & $\mathrm{x}$ & $\mathrm{x}$ \\
\hline
\end{tabular}


A comunidade quilombola Furnas da Boa Sorte tem se revelado como grupo em organização para um modelo de turismo que contribui para a afirmação do ecoturismo comunitário, solidário, inclusivo, justo e sustentável. Esses esforços contribuem no processo de autodeterminação e autoafirmação dos povos, conforme o Tratado de Educação Ambiental para Sociedades Sustentáveis e Responsabilidade Global. Através da conservação ambiental privilegiada pelo ecoturismo é uma maneira de reduzir a vulnerabilidade das comunidades frente aos impactos das mudanças climáticas e às desigualdades sociais. E isto está alinhado aos objetivos do desenvolvimento sustentável.

Observa-se que por um lado existem comunidades em organização para o ecoturismo de base comunitária e, por outro, pessoas interessadas em uma nova experiência de turismo que envolva a vivência com a natureza e com culturas locais sem que se altere o cotidiano das comunidades.

\begin{abstract}
Em um sentido mais amplo, no plano global, novas tendências tem marcado também a "ressignificação" do turismo, como, por exemplo, uma mudança sutil no perfil de turistas, conectados progressivamente com os temas da responsabilidade social e ambiental, o que passou a influenciar operadoras e agências internacionais, que, por sua vez, buscaram dar maior visibilidade a destinos turísticos menos convencionais, mas capazes de viabilizar novas experiências e descobertas para um "cidadão global", em busca de oportunidades de vivências e aprendizagens, para além do "cardápio" de opções disponíveis (IRVING, 2009).
\end{abstract}

De acordo com Layrargues (2018) existe alto e promissor potencial para o mercado do ecoturismo no Brasil, mas a questão é se teremos capacidade de aproveitá-lo não só como um valioso instrumento de proteção do patrimônio ambiental e cultural, mas também como uma oportunidade de promoção de ascensão social e distribuição de renda.

E mais, o que está em disputa não é somente o território e o que ele contém, mas também como o ecoturismo pode representar um instrumento de harmonização e de vínculo afetivo entre sociedade e natureza. Tuan (2015) considera que o turismo apreendido somente como utilidade social para o benefício econômico não é capaz de religar humanos à natureza. Segundo o autor, uma alternativa para apreciação mais duradoura da paisagem seria combinar a apreciação estética com a curiosidade científica. $E$ acrescente-se as vivências e experiências possíveis no lugar em referência à topofilia. Por vezes, aquilo que se apresenta como indiferente no cotidiano, seja a paisagem, um elemento natural e/ou uma comunidade, de repente podem se revestir de novo olhar, de novo sentido e novo valor antes despercebido. No birdwatching (observação de aves), essa sensação de despertamento e vivificação é chamado de lifer, o primeiro encontro com uma ave desconhecida ou que passava indiferente até aquele momento. $\mathrm{O}$ 
ecoturismo de base comunitária e a fruição da natureza podem trazer essa ressignificação.

Entre as perspectivas de futuro da comunidade quilombola de Furnas da Boa Sorte estão em pauta a criação de um núcleo de mulheres, o diálogo junto à associação da comunidade e a perspectiva de uma futura agência de turismo a ser criada e gerida pela comunidade para comercialização de pacotes em Ecoturismo de Base Comunitária. Tais perspectivas e incentivos contribuirão na autogestão do território, envolvendo o turismo e outros setores que potencializem a melhoria da qualidade de vida da comunidade.

Os percalços pelo caminho, são inúmeros, como intervalos no processo formativo, recurso financeiro escasso, pouco incentivo para assegurar uma transformação contínua ou imediata. No entanto, há esforços para que o processo permaneça vivo, mesmo que em passos lentos, vislumbrando um território justo e sustentável tendo como um dos elos norteadores o ecoturismo de base comunitária.

\section{Considerações finais}

A comunidade quilombola Furnas da Boa Sorte apresenta alto potencial para o desenvolvimento do ecoturismo de base comunitária. $O$ território se mostra rico em bens naturais e culturais, o qual pode ser gerido para os propósitos do ecoturismo de base comunitária. Durante todo o processo de diagnóstico e planejamento participativo percebeu-se que os meios de subsistência da comunidade podem estar alinhados à conservação ambiental, com possibilidade de gestão efetiva por agentes de proteção do patrimônio natural e cultural que são os próprios moradores da comunidade.

Entre os desafios estão a construção e fortalecimento de um modelo de empreendedorismo mais colaborativo, coletivo e cooperativo que seja eficaz e que assegure uma forma de distribuição de renda equitativa através do ecoturismo de base comunitária e não um modelo em que somente alguns atores sejam beneficiados e possibilite a concentração de renda.

Vale ressaltar a necessidade de políticas públicas que assegurem normas claras, que valorizem as comunidades e propiciem o fortalecimento das capacidades locais, gerando, dessa forma, a sustentabilidade de um modelo de turismo capaz de propiciar compartilhamento de responsabilidades e benefícios, desde que bem planejado e gerido.

A qualificação e formatação de roteiros integrados elaborados através do empoderamento da comunidade, a qualificação em comunicação, divulgação e marketing, a boa gestão e o controle das atividades turísticas no território quilombola, seguindo a perspectiva ética de desenvolvimento, também serão fortes instrumentos para o fortalecimento da identidade local. Tais instrumentos devem ser geridos pela própria comunidade, seja através de associação, agência turística ou núcleo de mulheres.

O ecoturismo de base comunitária permite vislumbrar a possibilidade de práticas de conservação e gestão responsável dos recursos naturais concorrendo para o aumento da qualidade de vida, redução da pobreza e proteção socioambiental. 


\section{Agradecimentos}

Somos gratas à WCS - Wildlife Conservation Society pelo apoio para o desenvolvimento do módulo de formação. S. Mamede agradece à Capes e Uniderp pela bolsa de estudos do Programa de Pós-Graduação em Meio Ambiente e Desenvolvimento Regional. Agradecemos à Alexine Keuroghlian e Maria do Carmo A. dos Santos pelo apoio e incentivo. À Comunidade Furnas da Boa Sorte pela hospitalidade, confiança e amizade. E a todos os participantes do I Módulo do Curso de Ecoturismo de Base Comunitária.

\section{Referências}

ALVES, G. L. Mato Grosso do Sul: o universal e o singular. Campo Grande: UNIDERP, 2003. 100p.

BURSZTYN, I. Planejamento turístico: políticas, processos e relacionamentos. Book review de Colin Michael Hall. Editora: Contexto, 2001. Caderno Virtual de Turismo, v. 4, n. 1, p. 1-4, 2004.

CASTRO, C. M; FORTUNATO, R. A. Redes populares de turismo e experiências de mapeamento participativo: a atuação da Rede Brasilidade Solidária em Teresópolis (RJ). Revista Continentes, v. 3, n. 5, p.150-161, 2014.

CORIOLANO, L. N. M. T. O turismo comunitário no nordeste brasileiro. Turismo de Base Comunitária: diversidade de olhares e experiências brasileiras. Rio de Janeiro: Letra e Imagem, p. 277-288, 2009.

CORIOLANO, L. N. M. T. O turismo nos discursos, nas políticas e no combate à pobreza. São Paulo: Annablume, 2006. 238 p.

CRUZ, R. C. A. Políticas públicas de turismo no Brasil: território usado, território negligenciado. Geosul, v. 20, n. 40, p. 27-43, 2005.

CRUZ, R. C. A. Turismo, produção do espaço e desenvolvimento desigual: para pensar a realidade brasileira. Aportes y Transferencias, v. 12, n. 2, p. 25-45, 2008.

DeCLERCK, F.; INGRAM, J. C.; Del-RIO, C.R. Introduction to Integrating Ecology and Poverty Reduction. In: DeCLERCK, F.; INGRAM, J. C.; Del$\mathrm{RIO}$, C. R. (eds.). Introduction to integrating ecology and poverty reduction: ecological dimensions. Springer: New York, p. 01-12, 2012.

EATON, D. P.; SANTOS, S. A.; SANTOS, M. C. A.; LIMA, J. V.; KEUROGHLIAN, A. Pecuária ecologicamente correta no Pantanal: usando pastejo rotacionado para aumentar o lucro e preservar um paraíso tropical.

Ciência Pantanal, v.1, n.1, p.07-10, 2014.

FREIRE, P. Educação como prática da liberdade. 28. ed. Rio de Janeiro: Paz e Terra, 2005. 158p.

GIRALDELLA, H.; NEIMAN, Z. Planejamento e gestão em áreas naturais protegidas. In: NEIMAN, Z.; RABINOVICI, A. (orgs.). Turismo e meio ambiente no Brasil. Barueri, SP: Manole, p. 124-148, 2010. 
HAESBAERT, R. O mito da desterritorialização: do "fim dos territórios" à multiterritorialidade. Rio de Janeiro: Bertrand Brasil, 2004. 395p.

IRVING, M. A. Ecoturismo em áreas protegidas: da natureza ao fenômeno social. In: COSTA, N. M. C.; NEIMAN, Z.; COSTA, V. C. (orgs.). Pelas trilhas do ecoturismo. São Carlos: Rima editora, p. 03-15, 2008.

IRVING, M. A. Reinventando a reflexão sobre turismo de base comunitária: inovar é possível? In: BARTHOLO, R.; SANSOLO, D.; BURSZTYN, I. (orgs.). Turismo de Base Comunitária: diversidade de olhares e experiências brasileiras. Rio de Janeiro: Letra e Imagem, p. 108-121, 2009.

KEUROGHLIAN, A.; SANTOS, M.C.A. Queixada! Que, quem, que é isso? Ciência Pantanal, v.1, n.1, p. 52-55, 2014.

LAYRARGUES, P. P. A função social do ecoturismo. Boletim Técnico do Senac, v.30, n.1, p. 38-45, 2018.

MALDONADO, C. O turismo comunitário na América Latina: gênesis, características e políticas. In: BARTHOLO, R.; SANSOLO, D. G.; BURSZTYN, I. (orgs.). Turismo de base comunitária: diversidade de olhares e experiências brasileiras. Rio de Janeiro: Letra e Imagem, p. 25-44, 2009.

MAMEDE, S. B.; BATISTA, F. R. Q.; BENITES, M. Da planície pantaneira às montanhas do Tumucumaque: a biodiversidade como potencial para 0 ecoturismo no Brasil. In: COSTA, N. M. C.; NEIMAN, Z.; COSTA, V. C. (orgs.). Pelas trilhas do ecoturismo. São Carlos: Rima editora, p. 269-296, 2008.

MAMEDE, S. B.; BENITES, M. Contemplação da fauna no Cerrado brasileiro: uso sustentável para o ecoturismo. In: COSTA, N. M. C.; NEIMAN, Z.; COSTA, V. C. (orgs.). Pelas trilhas do ecoturismo. São Carlos: Rima editora, p. 217-230, 2008.

MAMEDE, S.; BENITES, M.; SABINO, J.; ALHO, C. J. R. Ecoturismo na região turística Caminho dos Ipês: conexões entre identidade biofílica e usufruto dos serviços ecossistêmicos. Revista Brasileira de Ecoturismo, v. 10, n. 4, p.938-957, 2017.

MARUJO, N; CARVALHO, P. Turismo, planeamento e desenvolvimento sustentável. Turismo \& Sociedade, v. 3, n. 2, p. 147-161, 2010.

MENDONÇA, R.; NEIMAN, Z. Ecoturismo: discurso, desejo e realidade. In: NEIMAN, Z. (org.). Meio Ambiente, educação e ecoturismo. Barueri: Manole, p. 159-175, 2002.

RUSCHMANN, D. M. Turismo e planejamento sustentável: a proteção do meio ambiente. Campinas, São Paulo: Papirus, 1997. 199p.

SANCHO, A; IRVING, M. A. Interpretando o Plano Nacional de Turismo 2003/2007 sob a ótica da inclusão social. Caderno Virtual de Turismo, v. 10, n. 3, 2010.

TUAN, Y. Topofilia: um estudo da percepção, atitudes e valores do meio ambiente. Londrina: Eduel, 2015. 242 p. 
ZAMIGNAN, G.; SAMPAIO, C. A. C. Turismo de base comunitária como perspectiva para a preservação da biodiversidade e de modos de vidas de comunidades tradicionais: a experiência da micro-bacia do rio Sagrado, Morretes (PR). Encontro Nacional de Pós-Graduação e Pesquisa em Sociedade, v.5., 2010, Florianópolis. Anais eletrônicos... Florianópolis: UFSC, 2010. Disponível em: <http://anppas.org.br/encontro5/cd/artigos/GT1142-147-20100809214216.pdf>. Acesso em: 19 fev. 2019.

Maristela Benites: Instituto Mamede de Pesquisa Ambiental e Ecoturismo, Campo Grande, MS, Brasil.

E-mail: maris.benites@gmail.com

Link para o currículo Lattes: http://lattes.cnpq.br/7006699867493716

Simone Mamede: Instituto Mamede de Pesquisa Ambiental e Ecoturismo, Campo Grande, MS, Brasil.

E-mail: simone.mamede1@gmail.com

Link para o currículo Lattes: http://lattes.cnpq.br/726069416456047

Data de submissão: 11 de março de 2019

Data de recebimento de correções: 23 de março de 2019

Data do aceite: 23 de março de 2019

Avaliado anonimamente 